\title{
Construction design of apple sorter
}

\author{
Aleksander Nieoczym ${ }^{1}$, Jacek Caban ${ }^{2, *}$, Andrzej Marczuk ${ }^{2}$, and Frantiśek Brumerčik ${ }^{3}$ \\ ${ }^{1}$ Lublin University of Technology, Faculty of Mechanical Engineering, Department of Machine Design and Mechatronics, 36 \\ Nadbystrzycka Street, 20-618 Lublin, Poland \\ ${ }^{2}$ University of Life Sciences in Lublin, Faculty of Production Engineering, Department of Agricultural, Forestry and Transport \\ Machines, 28 Głęboka Street, 20-612 Lublin, Poland \\ ${ }^{3}$ University of Zilina, Faculty of Mechanical Engineering, Department of Design and Machine Elements, 1 Univerzitna Street, \\ 01026 Žilina, Slovakia
}

\begin{abstract}
When assessing the quality of fruit and packaging process, fruit-producing farms owners decide to evaluate fruit by people or automated sorting lines. The purchase of an automated sorting line generates high costs for the company, but it brings benefits in the form of increased work efficiency, and the better organization of fruit packaging and storage processes. The use of that machinery and equipment is common in agricultural farms as well as in fruit and vegetable processing companies. Despite the widespread use of various types of fruit sorters, the analysis of the operation of the designed device and the study of its technological parameters is still a current research problem. During operation of the devices for sorting fruit there are many technical problems affecting technological processes and quality of fruits. In order to improve the efficiency of sorting fruit, this process should be quickly and accurately. The purpose of this paper is to present the automated apple sorter line construction design, and software for quality controlling fruits. Selected elements of the sorter structure including endurance calculation using the Finite Element Method (FEM) and fruit control system using image analysis were presented.
\end{abstract}

\section{Introduction}

The development of technology and the related emergence of mechatronical devices causes that in each industry people are replaced by devices becoming more and more efficient. The human becomes a supervisor for work of the machinery. This supervision is not only mechanical maintenance but also checking on the correctness of the implementation of the programs implemented by the microprocessor. The use of machinery and equipment is also common in agricultural farms as well as in fruit and vegetable processing companies. Market pressure demanding a low-cost, highquality product means that agricultural companies are forced to replace human work with technically advanced machines [1]. In the case of devices for sorting fruit, optimisation of the operation line technology requires knowledge of the physical characteristics, relevant in the process of separation and sorting fruit so that with a minimum energy it would be possible to receive the final effect of the desired quality $[2,3]$. To assess the value of the operating conditions is used a number of approaches, due to the fact that in practice there are different circumstances allowing (or not) the application of certain methods [4]. Designed and built machines are of two types. The first one is a machine that only supports the sorting process, which is not complicated (which makes it cheaper) but does not exclude the use of the human factor. The second type of device is a device with multiple sorting mechanisms equipped with computercontrolled surveillance and vision systems. The most advanced technological lines for sorting fruit have several types of sorting devices, connected to the autonomous system that is capable of "learning" while doing work which translates into quality and significantly reduces the time of its tasks.

There are several types of sorting machines in the fruit processing equipment. Sentinel sorter by Odenberg company is created for two-way pre-sorting. Using this device it is possible to detect faults and foreign bodies in the fruit. This appliance is equipped with colour sensors and sensors type NIR, which are able to scan the surface of apples moving at a high speed. Thanks to it the sorter has a good quality of received image (which translates into the accuracy of the classification), and is maintained high efficiency of segregation [5].

Single-track sorting machine MONO by Sorter company is especially designed for use by small and medium-sized fruit growers. Thanks to their system it is able to sort the fruit by weight, form or colour depending on its program [6].

Cup sorting machine (CUP) allows the segregation of the fruit in terms of weight, size or colour of colouring. This device is one of the most advanced and the most productive machines of technological sorting line. It is possible to change the number of sorting tracks within

Corresponding author: jacek.caban@up.lublin.pl 
the range from two to twelve. Device software allows the continuous monitoring of the status of the sorting line and its performance [7].

The smaller processors do not decide to purchase the latest sorters. This is due to the high price of sorters and the cost of their servicing. Companies producing these machine in most cases have a monopoly on servicing their own devices due to various forms of patents and security of control programs. The consensus in this situation was to create a little complicated and relatively inexpensive machine that could automatically sort fruit, under the supervision of qualified worker but without more interference in this process.

\section{The draft of the sorting line}

Already at the stage of preparation of many processing processes in the chemical and food industry, the basic technical conditions of equipment are chosen for the demanded states of quality, form and geometrical dimensions $[8,9]$. The apple sorting line design is based on a single, rectilinear separating path where the fruits are sorted and routed to separate trays. The device is equipped with a container of $200 \mathrm{~kg}$ of fruit. The processing capacity of the entire sorting line is 1.5 tonnes of fruit per hour. The various components of the sorting line are described in Figure 1.

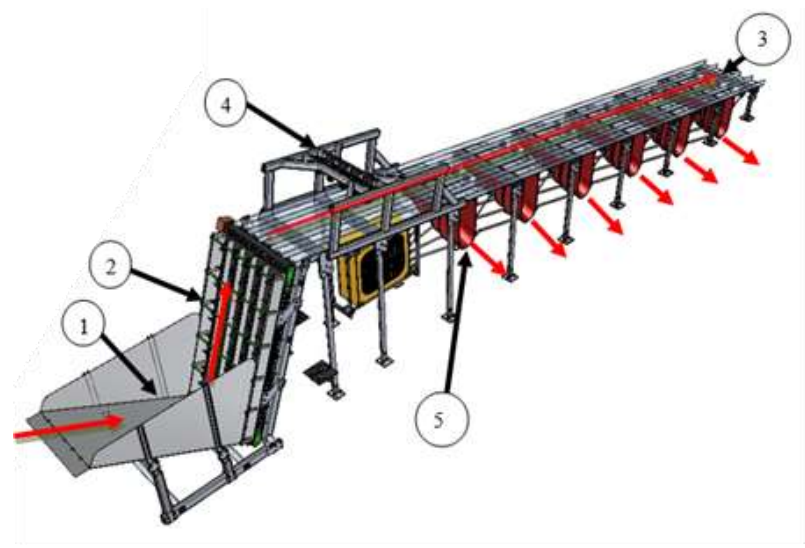

Fig. 1. Solid model of the sorting line for sorting apples (description in the text).

Apples not sorted are poured into the fruit container (1). Thus are transported using the conveyor belt (2), onto the ramp (3). The ramp is at an angle of $20^{\circ}$, so that the fruit may roll over freely. Over the upper part of the ramp are located AVT Oscar F-810C cameras (4), which take a series of photos of the ongoing fruit. Data from cameras are sent to the computer via wireless using the WLAN. The special program analyses the pictures and classifies fruit in accordance with standard [10]. After sorting, the computer sends a signal to the right SSKB05 driver of stepper motor, which opens the appropriate latch, using 5704X-01engine. When the latch opens, apples classified to the appropriate class fall down through the hole and roll down the gutters (5) to the box below, while the non-standard apples roll to the end of the ramp where they reach the waste container. The line allows to segregate into five selection classes.

\subsection{The transport system of non-segregated apples}

Model of the fruit container is shown in Figure 2. It consists of a plating made of stainless steel plate mounted on a support structure. The bottom of the plating is the floor (a). It is set at an angle of $30^{\circ}$ to the level in the direction of the conveyor belt so that the apples are able to slide towards the belt with a free movement. The floor plates folded at an angle of $90^{\circ}$ form the side walls (b). Above the floor there is a shelf (c), which is the back support for the crates, from which the fruit is poured into the container. The shelf is additionally reinforced with a stiffening (d), visible at the I enlargement. The lower part of the floor has notches (e) for the moving line landings. Above the notches, the sides of the container sheet are symmetrically bent at an angle of $90^{\circ}$ to the outside (f), and a number of holes ( $g$ ) are drilled on the resulting surface by which it is possible to fix the container to the outer wall of the conveyor belt.

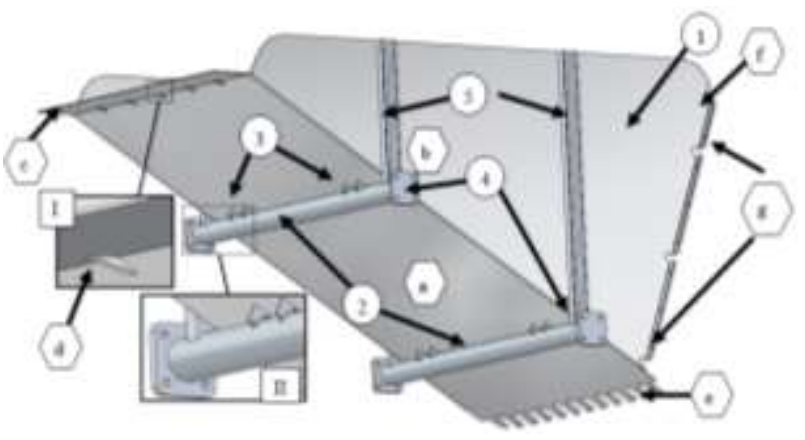

Fig. 2. Structural elements of the fruit container (description in the text).

The plating of the container (1) is based on pipes with a diameter of $\varnothing 50 \mathrm{~mm}$ (2). For a better connection of the flat surface of the sheet with the cylindrical surface of the pipe are welded on to both sides of the pipes network ribs (3), visible on the II enlargement. At the ends of the tubular profiles, are symmetrically welded flat bars (4) with holes for fixing the legs of the container. On the surface of the side walls have been added reinforcements (5) to stiffen the entire profile panel. The solid model showing the conveyor assembly together with the frame and the fruit container is shown in Figure 3. 




Fig. 3. The solid model of the conveyor with a frame and a container for fruit.

For the transport of fruit from the container onto the ramp is used the MINITrans H65 belt conveyor [11] with a length of $1500 \mathrm{~mm}$. The original conveyor belt was completely modified (Figure 4). Finger landings have been installed to transport apples at an angle from $0^{\circ}$ to $90^{\circ}$.

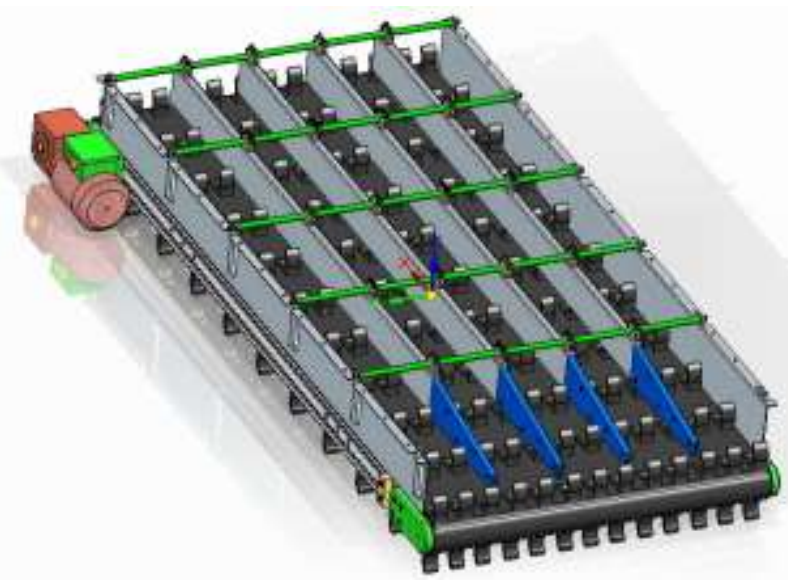

Fig. 4. The conveyor belt of the sorter.

\subsection{Segregation}

The solid model of the ramp is shown in Figure 5. The welded structure of the ramp (1) is the frame on which the ratchet mechanisms (2) are attached, and the frame (3) on which the cameras (4) are attached is mounted on the upper part. The structure is based on nine pairs of brackets (5), made of $\mathrm{C} 20 \times 40 \times 5$ C-profile. Between the supports on the inside of the ramp is a control box (6), which controls the motors of the ratchet mechanism. Complete ratcheting mechanism is shown in Figure 6.

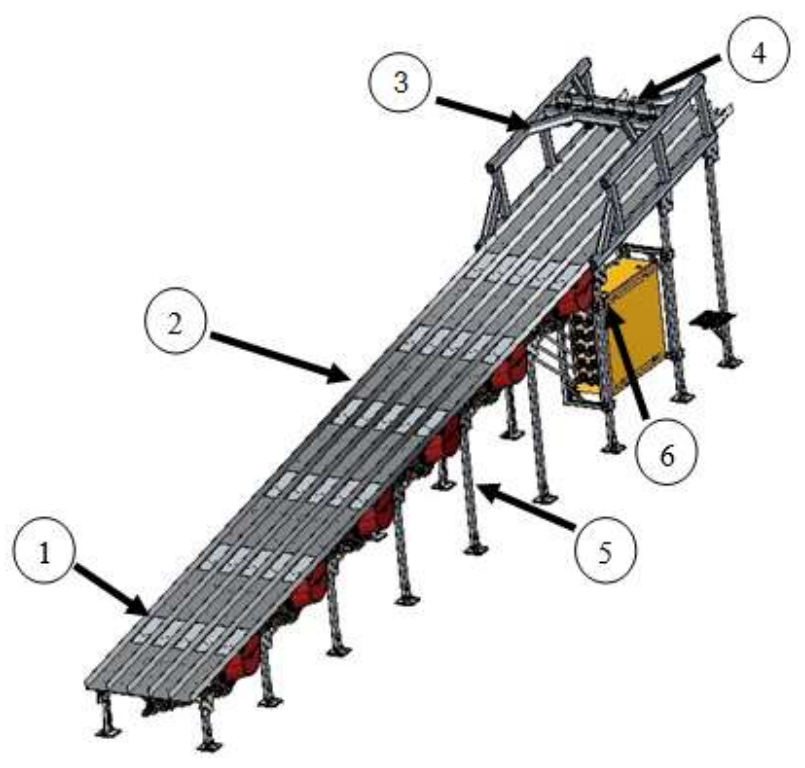

Fig. 5. The solid model of the ramp of the sorting line (description in the text).

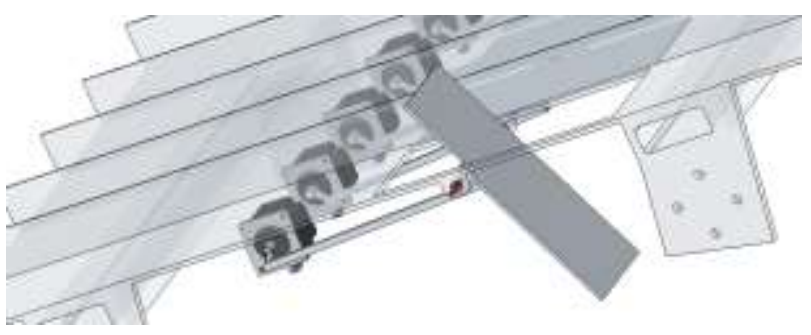

Fig. 6. View of the design of the ratchet.

The process of opening and closing individual latches uses electric motor 5704X-01 by Lin Engineering [12]. This engine is bipolar, powered by $24 \mathrm{~V}$ DC. SKK-B05 controller was used to control the electric motor $5704 \mathrm{X}$ 01 [13]. This device controls the motor via step and direction signals (STEP/DIR). Depending on the frequency of the pulses, the speed of the motor changes and depending on the number of pulses, the angle of rotation of the shaft changes.

As the optical sensor was used the AVT Oscar F $810 \mathrm{C}$ camera [14]. It has a high-speed interface (up to $400 \mathrm{MB} / \mathrm{s}$ ) and shutter for recording at 6.7 frames per second (at $1280 \times 960$ pixels), which significantly reduces the time course of the process of sorting single apples [1]. The camera has also features of automatic image processing. As a result, the images received are free of noise, with better sharpness and colour saturation.

\subsection{Strength analysis of selected sorter elements}

Endurance calculations were performed using the Finite Element Method (FEM). One of the busiest parts of the sorting line is the fruit container. The container (Fig. 7) is fixed in the holes for the M10 screws (1) and on the face surface of the container sheet (2) (where the structure is attached to the sheet profile of the outer wall of the conveyor belt). For an even distribution of the load on the whole surface of the floor of the container 
(3) was applied pressure of $200 \mathrm{~kg}$ of fruit. On the surface of the whole model was generated FEM net, whose characteristics are summarized in Table 1.

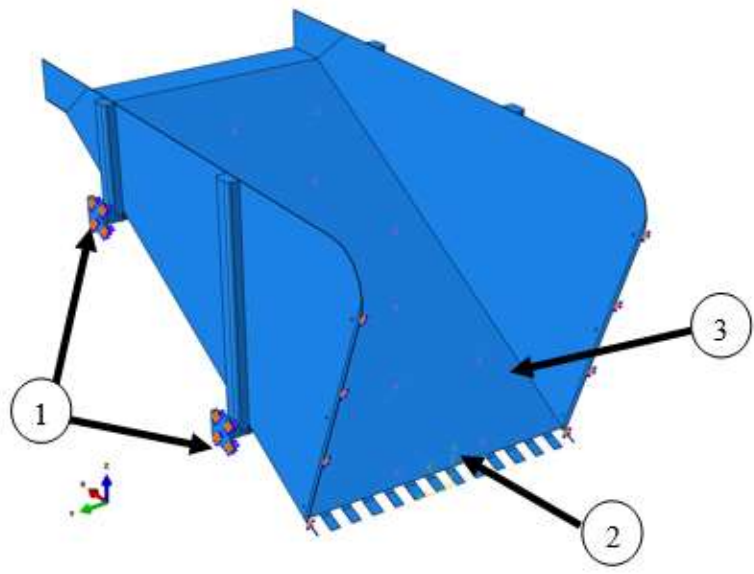

Fig. 7. Model of the container with marked resting places and place of application of pressure on the surface of the fruit container sheet.

Table 1. Setting Word's margins.

\begin{tabular}{|c|c|c|c|}
\hline Surface & Net type & $\begin{array}{c}\text { Number } \\
\text { of } \\
\text { nodes }\end{array}$ & $\begin{array}{c}\text { Number of } \\
\text { component } \\
\text { s }\end{array}$ \\
\hline $\begin{array}{c}\text { The side walls } \\
\text { of fruit } \\
\text { container sheet } \\
\text { and mounting } \\
\text { sheets }\end{array}$ & $\begin{array}{c}\text { tetragonal } \\
\text { of square } \\
\text { geometry }\end{array}$ & 75478 & 35295 \\
\hline $\begin{array}{c}\text { The floor of the } \\
\text { fruit container }\end{array}$ & $\begin{array}{c}\text { hexagonal } \\
\text { with linear } \\
\text { geometry }\end{array}$ & 75478 & 3988 \\
\hline
\end{tabular}

Maximum $50 \mathrm{MPa}$ reduced stresses were obtained on the surfaces of the holes for the fixing screws (item 1, Fig. 7) - Fig. 8.

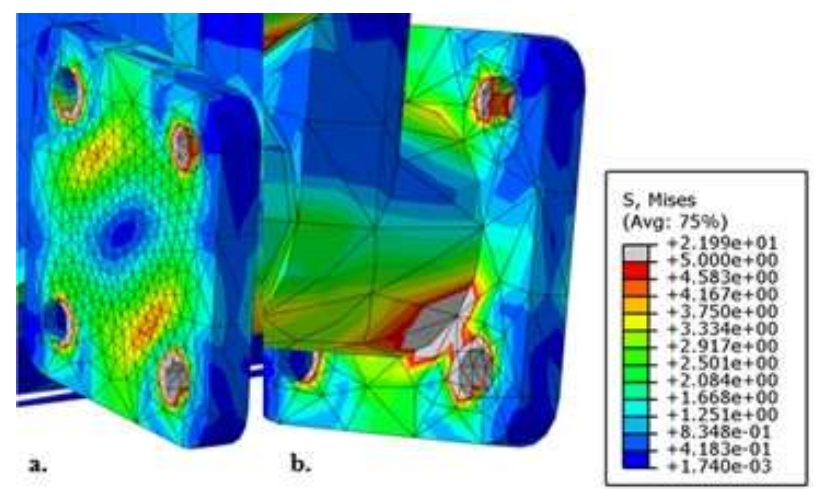

Fig. 8. Place of maximum stress.

Figure 9 shows the stress distribution on the floor surface of the container. Maximal values were obtained in the support areas of transverse tubes (1) and on the surface of the shelf (2).

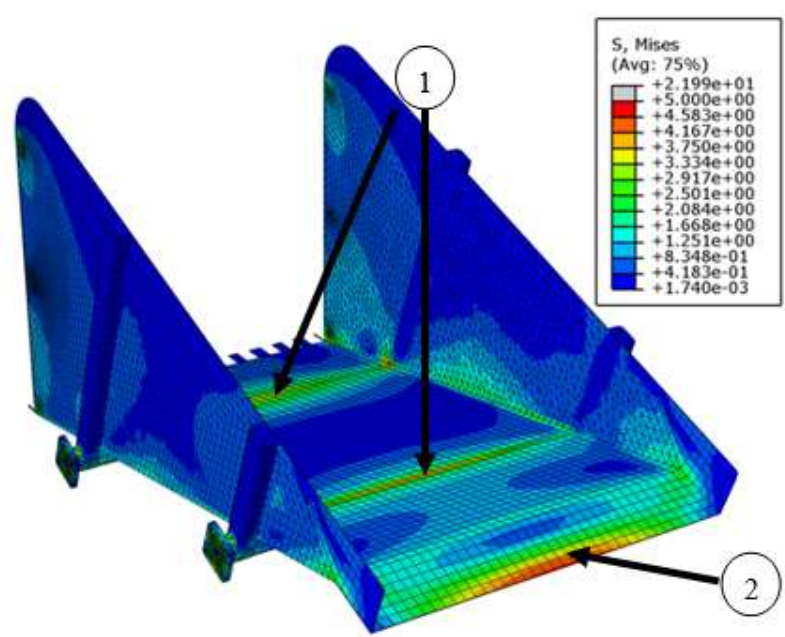

Fig. 9. Reduced stress distribution on the floor of the container.

\section{Program controlling the apple sorting process}

The control program analyses the photos taken from the camera of a single apple. It distinguishes in them identifying features such as the colour of the fruit, size, pits and fattening on its surface, and then classifies the fruit into the appropriate class. The identification of the fruit ends with sending a signal to the controller to open the corresponding latch. Many research works were devoted to issues of apples quality, including: [2, 15, 16, 17, 18, 19]. However, inspection for damaged, diseased, or contaminated fruit has been hindered by the inability to appropriately orient fruit for imaging and by lack of a method for imaging the whole of the surface of individual fruit [18]

There are many image study techniques. One such option is sub-pixel contour detection of the examined image [16]. Received image is filtered in order to detect the pixels on the border of the abrupt changes on the surface of the apples (pits, fattening). Next, the program, based on the generated pixels, connects them together to form a flat closed curve (Fig.10).
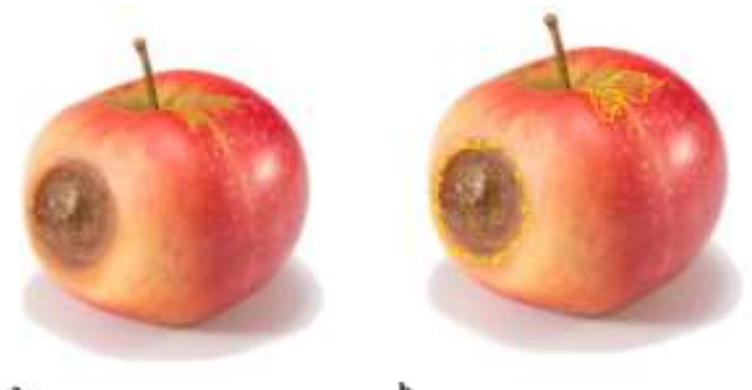

Fig. 10. Apple with marked fattening [16]: (a) visible defects; (b) interpretation of the program.

Another programmatic activity is the addition of the surface areas of the figures obtained and the classification of apples in the range of colour saturation to the corresponding class. High accuracy is achieved with the location of contour lines up to $1 / 50$ of a pixel. 
Due to the complexity of calculating the area of closed curves, while limiting the process time, an averaging algorithm can be used in the program to approximate the straight edges of the chaotically located pixels detected by subpixel contour detection.

An example of a program for fruit classification in the processing industry using subpixel contour detection is Ellips EFG 400 software [20]. This program is able to detect defects in fruit but also rate them in terms of the weight and size.

\subsection{The selected elements of controlling by EGF400 program}

Below are presented some selected tools for controlling the selection process of apples.

1 - The sorting method:

There are several sorting methods by: colour, size, weight, or combinations of these parameters (Fig. 11). It is possible to modify the standard modes and to change their parameters. It is also possible to create your own sorting procedures.

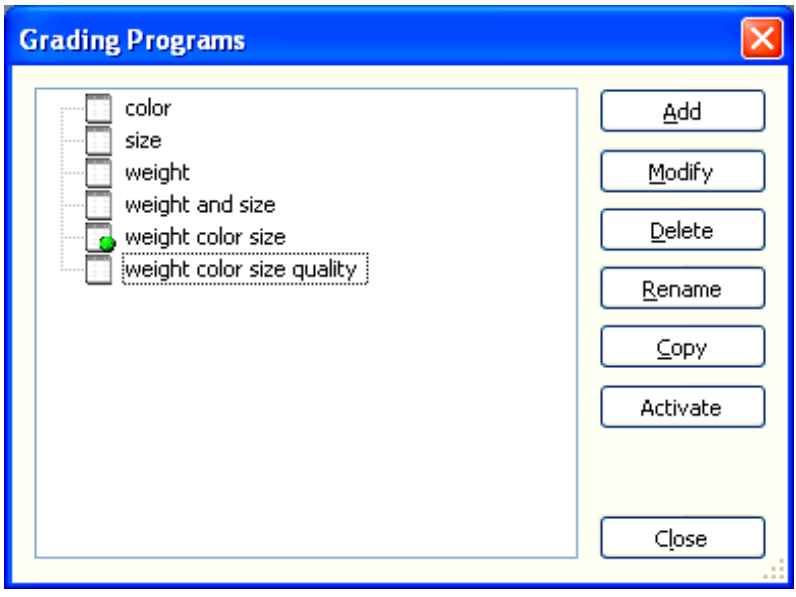

Fig. 11. Sort mode selection window [20].

2 - A quantitative evaluation of the sorting process:

Statistics window (Fig. 12), is equipped with three tabs: Grading Batch, Statistics Batch, and Machine Statistics. A table showing the statistics of each class is displayed and the statistics of the number of apples that do not fall into the standard. The table also shows the total statistics: total weight, percentage of line load, selection speed, grading time. It is possible to generate a chart that may represent the values associated with the work of the sorter.

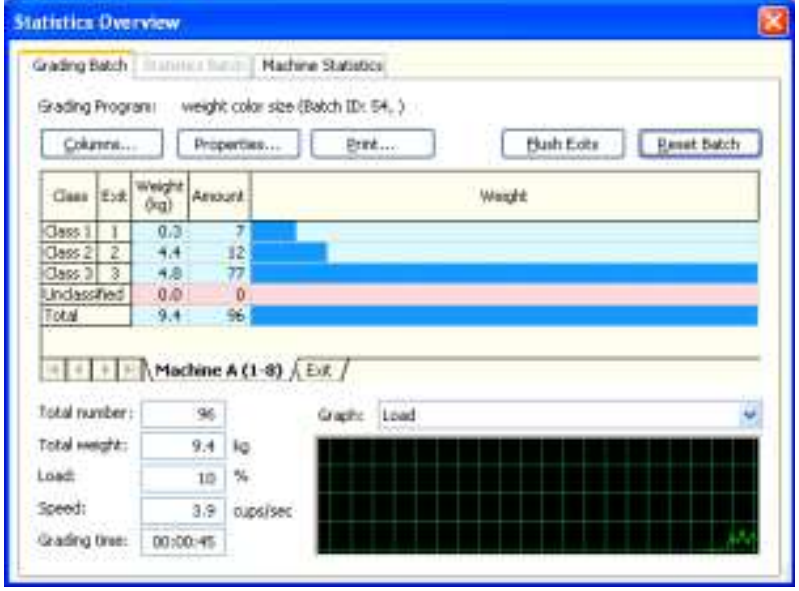

Fig. 12. Statistics window [20].

3 - Report on the measurements:

A window with a measurement table of all apples on a single section (Fig. 13), shows information about each fruit that has gone through the sorting process. The results in the table can be displayed on the basis of the sections or on the basis of selection method. An additional option provides the ability to change the filter measurements and colours - Fig. 14.

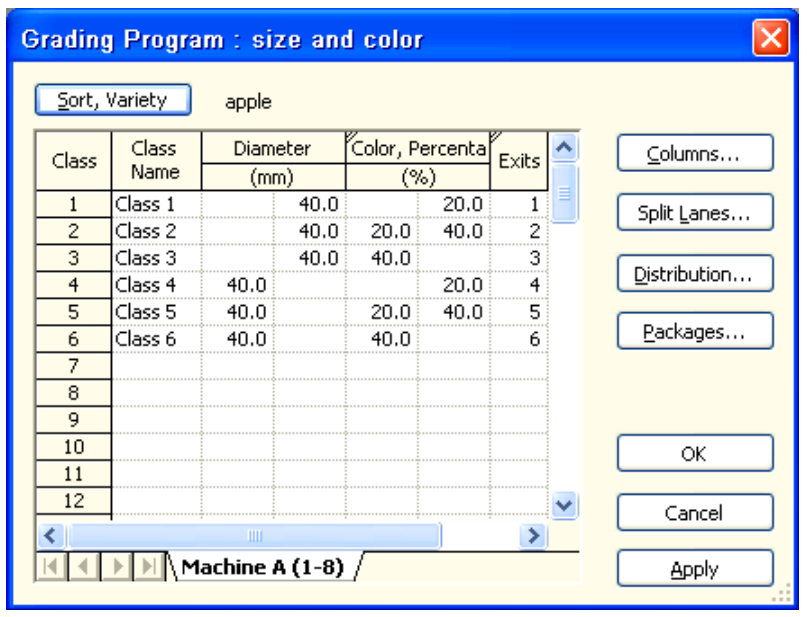

Fig. 13. The results of the sorting in terms of size and colour [20].

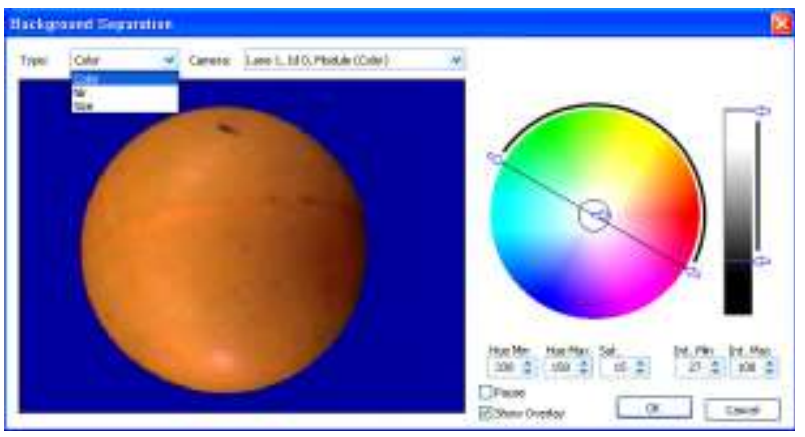

Fig. 14. Advanced base colour settings [20].

Thanks to its intuitive interface and wide range of settings, Ellips EFG 400 is not only suitable for apples but also for segregation of other fruits. Combining and editing selection modes allows you to sort different varieties and fairly accurately detect fruit defects. 


\section{Closing remarks}

The development of mechatronic systems for technological processes in agro-food industries, enforces need to design multifunctional constructions of highperformance. Also a very important factor in the assessment of the quality of the technological process is the condition of sorted fruit. Therefore, fruit inspection and sorting by human and automated imaging systems on the packaging lines are critical while packing premium quality fruits without any defects [17]. In case of apples, defects and disorders include arthropod damage (codling moth, mealybugs, aphid damage), postharvest diseases (blue mold, gray mold, mildew), physiological disorders (bitter pit, superficial scald, core flush), mechanical and field injuries (bruising, frost, hail damage), and fruit finish (sunburns). Damage is generally caused by impacts, vibrations, such processes as harvesting, transport, sorting and storage in bulk [21]. The presented design of the automated apple sorter meets the above mentioned technological and quality criteria.

\section{References}

1. A. Marczuk, Eksploatacja Niezawodność, Maintenance Reliability, 4, 82-90 (2009)

2. J. Jachimski, S. Mikrut, Próba subpikselowej lokalizacji linii konturowych $z$ wykorzystaniem drugiej pochodnej obrazu cyfrowego, AGH, Kraków (1998)

3. A.P. Kuczyński, Acta Agrophysica, 2, 4, 787-802 (2003)

4. A. Marczuk, J. Caban, P. Savinykh, N. Turubanov, D. Zyryanov, Eksploatacja Niezawodność, Maintenance Reliability, 19, 1, 121-125 (2017)

5. https://www.tomra.com/pl/solutions-andproducts/sorting-solutions/

6. http://www.sorter.pl/

7. http://www.sorter.pl/pl/automatyka/

8. J. Flizikowski, J. Sadkiewicz, A. Tomporowski, Przem. Chem. 94, 1, 69-75 (2015)

9. A. Tomporowski, M. Opielak, Eksploatacja Niezawodnosc, Maintenance Reliability, 14, 3, 222227 (2012)

10. Rozporządzenie komisji (WE) nr 1221/2008. http://www.lex.europa.eu

11. http://www.iwb-industrietechnik.de/pl/

12. www.linengineering.com/contents/stepmotors/pdf/5 704.pdf

13. http://www.akcesoria.cnc.info.pl/sterowniki silniko w krokowych.htm.

14. www.alliedvisiontec.com

15. B.S. Bennedsen, D.L. Peterson, A. Tabb, Comput. Electron. Agr. 48, 92-102 (2005)

16. A. Groborz, P. Kiełbasa, Inżynieria Rolnicza, 9, 10, $117-126(2005)$
17. S. Jarolmasjed, C.Z. Espinoza, S. Sankaran, L.R. Khot, Postharvest Biol. Tec. 118, 35-42 (2016)

18. A.M. Lefcourt, P. Narayanan, U. Tasch, M.S. Kim, D. Reese, R. Rostamian, Y.M. Lo, Biosyst. Eng. 104, 64-71 (2009)

19. J.A. Throop, D.J. Aneshansley, W.C. Anger, D.L. Peterson, Postharvest Biol. Tec. 36, 281-290 (2005)

20. www.fruittek.com/fruit-packing.../ellips-visionsorting.html

21. P. Komarnicki, R. Stopa, M. Młotek, Inżynieria Rolnicza, 2, 3, 145-157 (2013) 